\title{
ESTUDIO DE LA BIODEGRADACIÓN DE RESIDUOS DE ACEITE LUBRICANTE RETENIDOS EN BENTONITA USANDO EL CONSORCIO BACTERIANO OIL EATING MICROBES (Rodhococus, Pseudomonas y Bacillus)
}

Jaqueline Chirre Flores ${ }^{* a}$, Alejandro Patiño Gabriel ${ }^{\mathrm{b}}$, Raymundo Erazo Erazo ${ }^{\mathrm{a}}$

\section{RESUMEN}

La inadecuada disposición final de residuos industriales peligrosos, tal como la bentonita usada en los procesos de refinación de lubricantes automotrices contaminados, genera una serie de impactos ambientales negativos en los recursos agua, aire y suelo. Para contribuir en la minimización de estos impactos, el propósito de la presente investigación fue evaluar la capacidad de biodegradación de una muestra de aceite lubricante automotriz atrapado en arcilla bentonita, utilizando el consorcio bacteriano Oil Eating Microbes (Rodhococus pyridinivorans, Pseudomonas montielli y Bacillus sp.).

Para obtener el máximo rendimiento de la biodegradación del aceite (reducción de hidrocarburos totales de petróleo en la arcilla), por el consorcio bacteriano, se realizaron dos pruebas experimentales en un biorreactor de 5 litros de capacidad, donde se midieron la concentración de biodegradación de hidrocarburos totales de petróleo, la primera se realizó durante 13 días y la segunda en 59 días: se obtuvo rendimientos de menos del $2 \%$ y $50 \%$ para la primera y segunda prueba, respectivamente, lo que muestra la reducción de la contaminación de la arcilla bentonita contaminada.

Palabras clave: Aceites lubricantes usados, biodegradación, arcillas bentonita.

\section{STUDY OF THE BIODEGRADATION OF RESIDUES OF LUBRICANT OIL RETINED IN BENTONITA USING THE BACTERIAL OIL EATING MICROBES CONSORTIUM (Rodhococus, Pseudomonas and Bacillus)}

\begin{abstract}
The inadequate final disposal of hazardous industrial waste, such as bentonite used in the refining processes of contaminated automotive lubricants, generates a series of negative environmental impacts on water, air and soil resources. To contribute to the minimization

\footnotetext{
a Facultad de Química e Ingeniería Química, Universidad Nacional Mayor de San Marcos, Lima Perú, jaqui chirreflores@yahoo.es

b Facultad de Ciencias Biológicas, Universidad Nacional Mayor de San Marcos.
} 
of these impacts, the purpose of the present investigation was to evaluate the biodegradation capacity of a sample of automotive lubricating oil trapped in bentonite clay, using the bacterial consortium Oil Eating Microbes (Rodhococus pyridinivorans, Pseudomonas montielli and Bacillus sp.).

To obtain the maximum performance of the biodegradation of the oil (reduction of total hydrocarbons of oil in the clay), by the bacterial consortium, two experimental tests were carried out, in a five liter capacity bioreactor, where the concentration of biodegradation of total petroleum hydrocarbons was measured, the first was performed for 13 days and the second in 59 days: less than $2 \%$ and $50 \%$ yields were obtained for the first and second tests respectively, which shows the reduction of contamination of the contaminated bentonite clay, which is one of the environmental problems that it is desired to eliminate, since they cause air, water or soil pollution, affecting the ecosystems both aerial, aquatic or terrestrial.

Key words: Used lubricating oils, biodegradation, bentonite clays.

\section{INTRODUCCIÓN}

El aceite lubricante usado (ALU) es todo aceite que ha sido utilizado y se encuentra contaminado con impurezas físicas o químicas y no reúne las condiciones óptimas para el fin para el cual fue producido inicialmente. Los aceites lubricantes usados son considerados residuos peligrosos y existen diversas opciones para disminuir su peligrosidad, pero lo más importante es poder eliminar sus impurezas físicas y químicas, para recuperar el aceite base lubricante. El método tradicional ácido-arcilla, genera una gran cantidad de arcillas contaminadas, que no son reaprovechadas. Las arcillas tipo bentonitas, consideradas como suelos arcillosos montmorilloníticos, son altamente plásticos y expansivos (Duque y Escobar, 2013). Se utilizan como medio filtrante para decolorar aceites lubricantes usados de origen mineral y, luego de esto, la arcilla queda como un residuo contaminado con aceite.

Según Venosa et al. (1999), las bacterias gram negativas parecen encontrarse más adaptadas a estas fuentes de carbono. Haritash et al. (2009), estudiaron la biodegradación de hidrocarburos aromáticos policíclicos (PAH), como se muestra en la figura 1. Algunas de las especies bacterianas conocidas para degradar PAHs son las siguientes: Pseudomonas aeruginosa, Pseudomonas fluoresens, Mycobacterium spp., Haemophilus spp., Rhodococcus spp., Paenibacillus spp. 


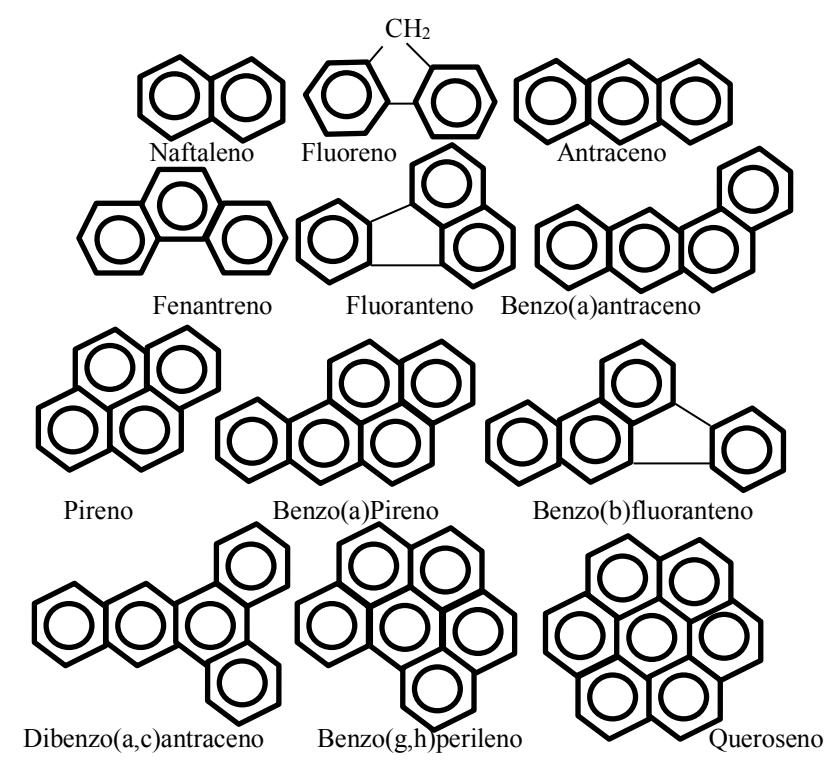

Figura 1. Estructura química de algunos PAHs comúnmente estudiados (Haritash etal., 2009).

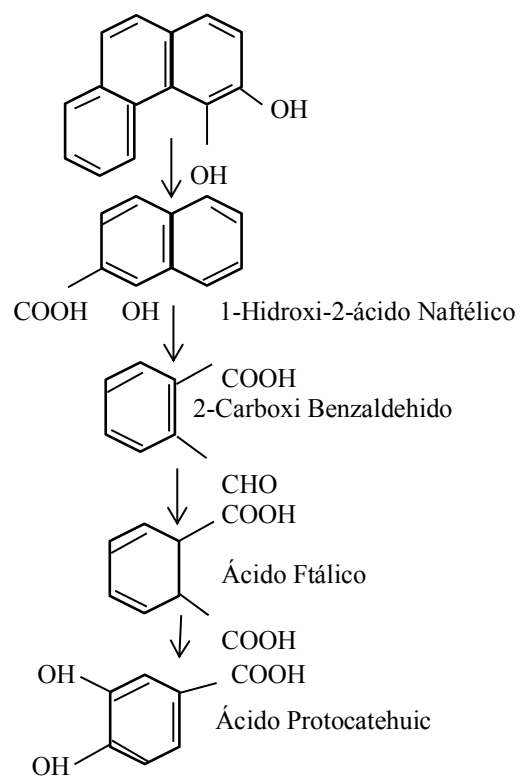

Figura 2. Degradación propuesta del 3,4 - dihidroxi - fenantreno por Mycobacterium sp. cepa KR2 (Haritash etal., 2009). 
La biodegradación de los PAHs ha sido observada tanto en condiciones aeróbicas como anaeróbicas y la tasa puede ser mejorada por pretratamiento físico y químico en suelos contaminados. En la figura 3 se muestra la biodegradación anaeróbica.

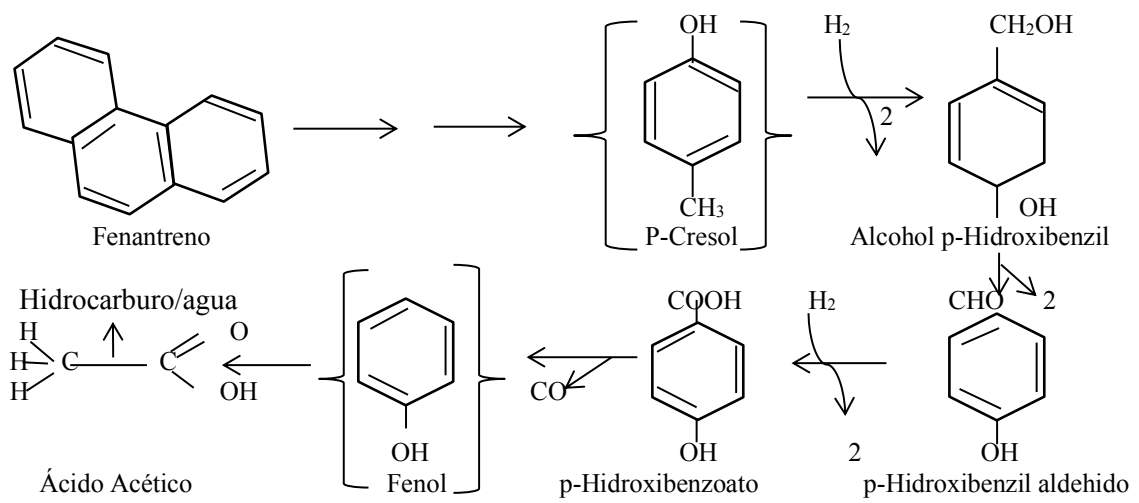

Figura 3. Biotransformación anaeróbica del fenantreno por bacterias sulfato-reductoras (Haritash et al., 2009).

El presente estudio experimental se realizó tomando como referencia el modelo matemático de Medina S. et al. (2009), que estudia la biodegradación de hidrocarburos en suelos contaminados, utilizando los fenómenos de difusión, sorción y biodegradación en un reactor de lodos de hidrocarburos.

\section{PARTE EXPERIMENTAL}

El aceite contaminado presente en la arcilla se removió mediante el proceso de biodegradación de hidrocarburos con un consorcio de bacterias. Este proceso se realizó en un biorreactor en el cual se proporcionó las condiciones adecuadas al medio de cultivo para que la velocidad de reproducción de las bacterias sea la óptima.

\section{El procedimiento experimental se realizó de la siguiente manera:}

1.- Determinación de la cantidad de aceite lubricante usado presente en la arcilla.

2.- Aislamiento y caracterización de las cepas del consorcio liofizado.

3.- Crecimiento del consorcio bacteriano degradador.

4.- Siembra y evaluación de la biodegradación del consorcio en un biorreactor.

5.- Cuantificación de la cinética de crecimiento y biodegradación de los hidrocarburos.

\section{Breve descripción de las etapas del procedimiento:}

1.- Determinación de la cantidad de aceite lubricante usado presente en la arcilla

Extracción de hidrocarburos totales de petróleo se realizó con el equipo de Soxhlet, de acuerdo a la técnica 3540 de la EPA y la medición se hizo mediante el método gravimétrico. 
Una muestra de 5 gramos de arcilla contaminada fue envuelta con pabilo y se utilizó éter etílico como solvente a una temperatura de $60^{\circ} \mathrm{C}$ durante 12 horas.

Después de 12 horas, se evaporó el éter y se determinó la cantidad de aceite, contenida en el balón.

\section{Aislamiento y caracterización de las cepas del consorcio liofizado}

La descripción de los microorganismos es relevante para elevar la certeza de la pureza de su uso durante la producción del consorcio.

El aislamiento de las cepas contenidas en el producto "Oil Eating Microbes" se realizó con la finalidad de identificar, purificar y obtener bacterias cuantificables. Se sembró 0,5 gramos del contenido de la pastilla en un tubo con $10 \mathrm{~mL}$ de caldo nutricio (Himedia) y otros 0,5 gramos en un tubo con $10 \mathrm{~mL}$ de caldo acetamida (Merck). Ambos tubos se incubaron a $30^{\circ} \mathrm{C}$ durante 27 horas.

El crecimiento producido en el tubo con caldo nutricio (Himedia) se estrió en dos placas de agar nutriente y el crecimiento producido en el tubo con caldo acetamida se estrió en dos placas de agar King B; todas las placas fueron incubadas a $30^{\circ} \mathrm{C}$ por 48 horas.

\section{3.- Crecimiento del consorcio bacteriano degradador}

Luego de caracterizar las cepas del consorcio, se dieron las condiciones necesarias para el crecimiento de las bacterias: para el crecimiento de Pseudomonas montielli se usó un medio inductor de lipasas (glucosa $15 \mathrm{~g} / \mathrm{L}$, glicerol $10 \mathrm{~g} / \mathrm{L}$, extracto de levadura $3 \mathrm{~g} / \mathrm{L}$, peptona de carne $5 \mathrm{~g} / \mathrm{L}, \mathrm{K} 2 \mathrm{HPO} 40,3 \mathrm{~g} / \mathrm{L}, \mathrm{NaCl} 0,5 \mathrm{~g} / \mathrm{L}$ y estabilizado a $\mathrm{pH} 7,0$ ), el cual fue preparado en un volumen de $500 \mathrm{~mL}$ e inoculado con $10 \mathrm{~mL}$ de una suspensión de 105 células $/ \mathrm{mL}$. Igualmente para Bacillus licheniformis y Rhodococcus pyridinivorans se utilizó un medio nutricio fortificado con glicerol (glucosa $20 \mathrm{~g} / \mathrm{L}$, glicerol $5 \mathrm{~g} / \mathrm{L}$, extracto de levadura $5 \mathrm{~g} / \mathrm{L}$, sulfato de amonio $0,5 \mathrm{~g} / \mathrm{L}$, fosfato monopotásico $0,4 \mathrm{~g} / \mathrm{L}, \mathrm{NaCl} 0,5 \mathrm{~g} / \mathrm{L}$, sulfato de magnesio $0,5 \mathrm{~g} / \mathrm{L}$; sulfato de manganeso $0,02 \mathrm{~g} / \mathrm{L}$ y estabilizado a $\mathrm{pH} 7,0)$, los cuales fueron preparados en dos matraces, en volúmenes de $500 \mathrm{~mL}$ e inoculado con $10 \mathrm{~mL}$ de una suspensión de $10^{5}$ células/mL de cada cepa. Todos los caldos fueron incubados por 48 horas a una temperatura de $30^{\circ} \mathrm{C}$ y $150 \mathrm{rpm}$. Luego de culminado el crecimiento se mezclaron en una botella estéril todos los cultivos y agitados durante 3 horas a $150 \mathrm{rpm}$. Este fue el consorcio para las evaluaciones de degradación.

\section{4.- Siembra y evaluación de la biodegradación del consorcio en un biorreactor}

En un biorreactor de 5 litros de capacidad (figura 7), de acero inoxidable A-304, con agitador mecánico, lectura de la velocidad del impulsor (120 rpm), sistema de mamparas y difusor circular de aire, un compresor metálico con aire esterilizado mediante un filtro bacteriológico de $0,45 \mu \mathrm{m}$; para inyectar $50 \mathrm{~L} / \mathrm{min}$ de aire. Asimismo, el equipo cuenta con un calentador que es controlado a $35^{\circ} \mathrm{C}$. 
Una muestra de 1,5 kilos de arcilla bentonita saturada, fue colocada en un biorreactor, luego se adicionó 4,5 L de agua destilada mezclando completamente. Esta mezcla se llevó a pH 7,0 con la adición de una solución de $\mathrm{NaOH}, 1 \mathrm{M}$, y luego se inoculó un volumen de consorcio igual al $10 \%$ del volumen total de agua (Pseudomonas montielli con 3,4 x10 $0^{8} \mathrm{cel} / \mathrm{mL}$; Bacillus licheniformis con $1,9 \times 10^{8} \mathrm{cel} / \mathrm{mL}$; y Rhodococcus yridinivorans con $8,2 \times 10^{8} \mathrm{cel} / \mathrm{mL}$ ).

Se tomaron muestras cada $24 \mathrm{~h}$, para medir el rendimiento de la biodegradación, de acuerdo al método gravimétrico de equipo Soxhlet 3540 de la EPA.

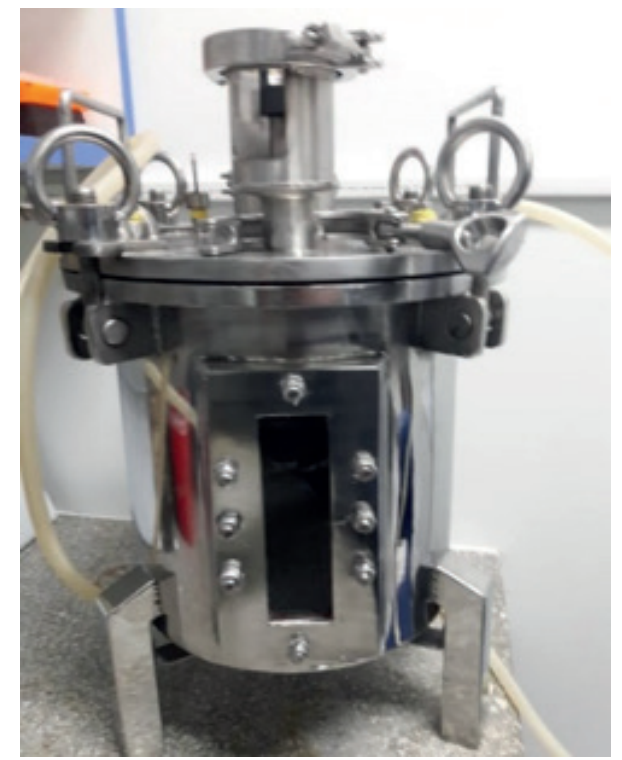

Figura 4. Reactor biológico de $5 \mathrm{~L}$ en acero inoxidable.

5.- Cuantificación de la cinética de crecimiento y biodegradación de los hidrocarburos

Se tomó una muestra cada 24 h, para la medición del crecimiento microbiano mediante la técnica de diluciones y siembra por diseminación en agar Cetrimide para Pseudomonas e Hicrome para el resto de bacterias, entre ellas los heterótrofos viables acompañantes de la flora de la arcilla.

Las pruebas experimentales confiables, realizadas para la biodegradación de hidrocarburos totales de petróleo, fueron dos procesos batch, durante un período de tiempo de 13 y 59 días, respectivamente. 


\section{RESULTADOS Y DISCUSIÓN}

Los resultados del aislamiento y caracterización de las cepas son los siguientes:

- Rhodococcus Pyridinivorans:

Se logró aislar esta bacteria del producto, caracterizándose por tener colonias puntiformes elevadas con bordes lisos y una coloración parduzca (figura 5).

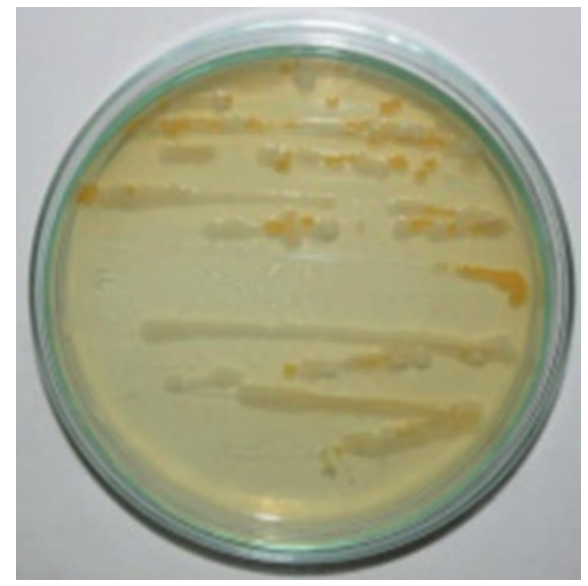

Figura 5. Rhodococcus pyridinivorans en un agar nutricio.

- Pseudomonas Montielli:

Las colonias son circulares, de borde liso, mucosas y de aspecto húmedo y con pigmentación verduzca fosforescente (figura 6).

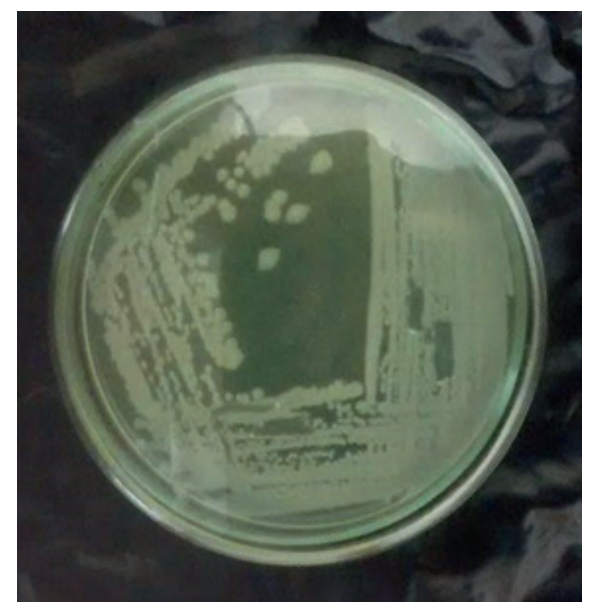

Figura 6. Pseudomonas montielli aislada en agar cetrimide. 
- $\quad$ Bacillus licheniformis:

Las colonias de esta bacteria son de borde lobulado, ligeramente festoneado, superficie rugosa, color blanquecino (figura 7).

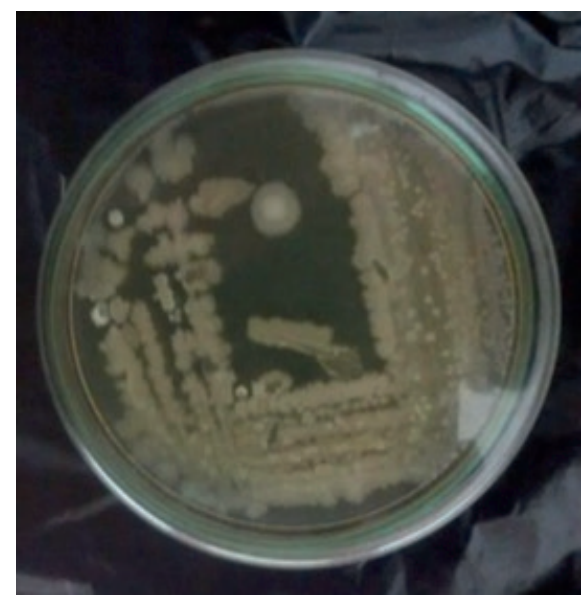

Figura 7. Bacillus Licheniformis en agar nutricio.

\section{Producción del consorcio bacteriano degradador}

Se logró un consorcio microbiano con las concentraciones: Pseudomonas montielli con 3,4 $\mathrm{x} 10^{8} \mathrm{cel} / \mathrm{mL}$; Bacillus licheniformis con $1,9 \times 10^{8} \mathrm{cel} / \mathrm{mL}$; $\mathrm{y}$ Rodococcus pyridinivorans $\mathrm{con}$ $8,2 \times 10^{8} \mathrm{cel} / \mathrm{mL}$.

\section{Cuantificación de la cinética de crecimiento y degradación de los hidrocarburos}

Durante el desarrollo del proceso de degradación de la primera prueba experimental, se evidenció un aumento de las cepas del consorcio microbiano a partir de los 3 días; el cual se extendió hasta el día 10, momento desde el cual se estableció un crecimiento estacionario y se evidenció una elevación del porcentaje de degradación de hidrocarburos presentes. También hubo un crecimiento de las bacterias heterótrofas viables, que son las que se encuentran en el medio ambiente, las cuales no interrumpieron en la actividad degradativa ya que su crecimiento no fue considerable con respecto al resto de bacterias del consorcio.

La muerte bacteriana se dio pasados los 13 días en la primera prueba experimental, iniciando primero con el género Rhodococcus y Pseudomonas; y manteniéndose la presencia del género Bacillus; ya que estos últimos poseen estructuras de permanencia o latencia llamadas esporas (figura 8). 


\section{$\mathrm{UFC} / \mathrm{mL}$}

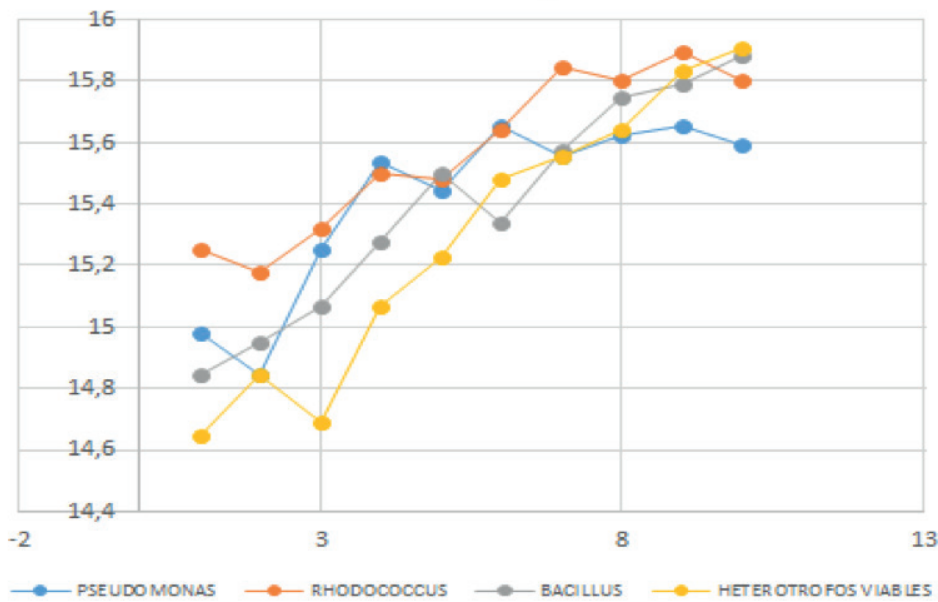

Figura 8. Cinética de crecimiento de bacterias en UFC/mL en función del tiempo de la primera prueba experimental. (Elaboración propia).

En la segunda prueba experimental, la muerte bacteriana se observó luego de 45 días, iniciándose primero con el género Rhodococcus y Bacillus; y manteniéndose la presencia del género Pseudomonas (figura 9).

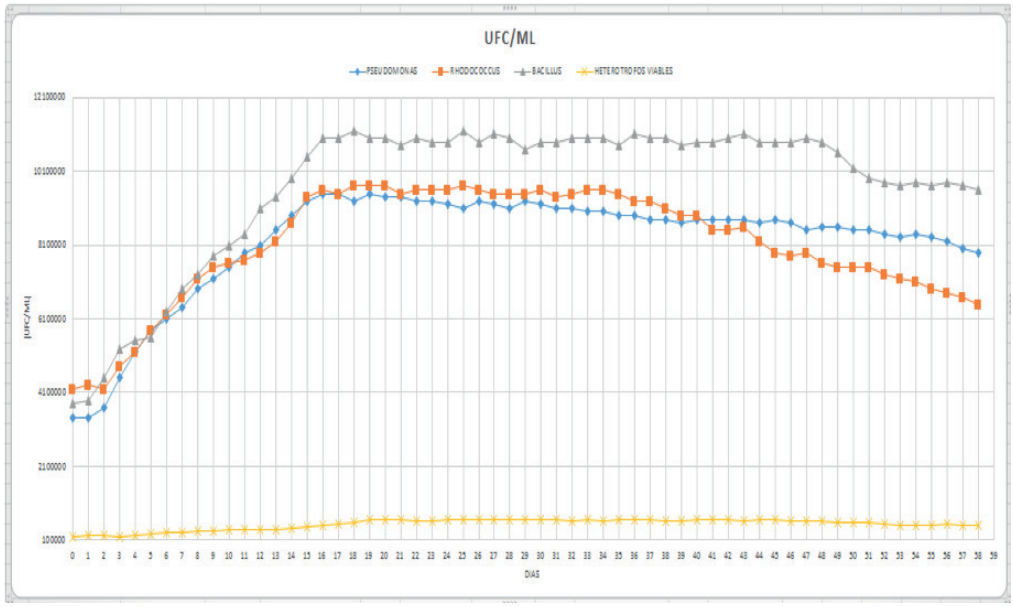

Figura 9. Cinética de crecimiento de bacterias en $\mathrm{UFC} / \mathrm{mL}$ en función del tiempo de la segunda prueba experimental. (Elaboración propia). 
La concentración de hidrocarburos totales de petróleo en gramos, se cuantificaron en el equipo de Soxhlet, de acuerdo a la técnica 3540 de la EPA y la medición se hizo mediante el método gravimétrico.

El rendimiento de biodegradación de hidrocarburos totales de petróleo (HTP), se realizó mediante la fórmula:

$$
\left(1-\frac{\text { Peso final })}{\text { Peso inicial }} * 100 \%\right.
$$

En la biodegradación de los HTP en la primera prueba experimental se evidenció una elevada actividad a partir de los 9 días de actividad, logrando un máximo de 1,85\% a los 13 días. En cuanto a la degradación de los HTP de la segunda prueba experimental se obtuvo una elevada actividad a partir de los 8 días, logrando un maximo de $50 \%$ a los 59 días como se muestra en la tabla 1.

Figura 1. Concentración de HTP (g) y \% de biodegradación de los hidrocarburos totales de petróleo (HTP) en el tiempo de las dos pruebas experimentales.

\begin{tabular}{ccc}
\hline $\begin{array}{c}\text { Tiempo } \\
\text { (días) }\end{array}$ & $\begin{array}{l}\text { Concentración de } \\
\text { HTP (g) }-\mathbf{( \% ) ~ d e} \\
\text { biodegradación): } \\
\text { 1ra. Prueba }\end{array}$ & $\begin{array}{l}\text { Concentración de } \\
\text { HTP (g) }-(\% \text { de } \\
\text { biodegradación): } \\
\text { 2da. Prueba }\end{array}$ \\
\hline 0 & 2.002 & 1.961 \\
1 & $1.998-(0.19)$ & $1.950-(0.56)$ \\
2 & $1.923-(1.94)$ \\
5 & $1.979-(1.15)$ & $1.792-(8.62)$ \\
6 & $1.965-(1.85)$ & $1.615-(17.64)$ \\
8 & & $1.506-(23.20)$ \\
9 & & $1.021-(47.93)$ \\
13 & & $0.987-(49.67=50)$ \\
15 & & \\
21 & & \\
45 & & \\
59 & & \\
\hline
\end{tabular}


Se obtuvo una reducción de menos del $2 \%$ de hidrocarburos totales de petróleo en la primera prueba experimental con una dilución de arcilla: agua de 1:1, mientras que en la segunda con una dilución en arcilla: agua de 1:3, se obtuvo un 50\% de biodegradación del aceite lubricante usado que se encuentra en la arcilla contaminada.

Se concluye que la segunda prueba experimental, realizada durante 59 días, se obtuvo un mejor resultado de biodegradación de $50 \%$, en comparación con la primera prueba experimental realizada en 13 días, se obtuvo menos del $2 \%$ de biodegradación de hidrocarburos totales de petróleo.

Nuestros resultados son bastante alentadores cuando comparados a los obtenidos por Lee et al. (2006), después de 105 días, se obtuvo una reducción de 42-51\% de hidrocarburos totales de petróleo; en el caso de Xu et al. (2013), después de 18 días se redujo en 53\%; y Karamalidis et al. (2010), después de 191 días se obtuvo una reducción de 94\%, a diferentes condiciones de operación.

\section{CONCLUSIONES}

Para el presente estudio, se puede concluir que se obtuvo una reducción del $50 \%$ de hidrocarburos totales de petróleo, lo que va a influir en la eliminación de los contaminantes de la arcilla, lo que permitirá preservar el medio ambiente.

El método empleado permite reutilizar la arcilla contaminada y, por consiguiente, reducir la cantidad de recursos no renovables empleados en el tratamiento de aceites lubricantes contaminados.

\section{AGRADECIMIENTO}

Nuestro agradecimiento a los directores de los Laboratorios de la Facultad de Ciencias Biológicas y de la Facultad de Química e Ingeniería Química de la Universidad Nacional Mayor de San Marcos, por brindar sus instalaciones para realizar las pruebas y mediciones del presente estudio. 


\section{REFERENCIAS BIBLIOGRÁFICAS}

1. Aitken M. Mechanisms of organic pollutant transformation and degradation by microorganisms. En Bioremediation: Principles and Practice. Volumen I: Fundamentals and Applications. Editado por Sikdar S, Irvine R. Pennsylvania: Technomic Publication; 1998. 333-383.

2. D.S. N N $^{\mathrm{0}}$ 57-2004 PCM. Plan Integral de Manejo de Residuos Sólidos en Osinergmin. Área de Seguridad y Aspectos Ambientales. Lima: OSINERGMIN; 2014.

3. Duque E, Escobar C. Origen, formación y construcción del suelo, fisicoquímica de las arcillas. [Internet] Capítulo 1; 2013. [Citado 22 feb 2019]. Disponible en: http://www. bdigital.unal.edu.co/1864/2/cap1.pdf

4. Haritash A, Kaushik C. Aspectos de Biodegradación de Hidrocarburos Aromáticos Policíclicos (PAHs), India: a review. J Hazard Mater. 2009; 169:1-15.

5. Estrucplan. Informe Técnico sobre Aceites Usados y sus Usos. [Internet]. Buenos Aires; 2011. [Citado 11 may 2019]. Disponible en: https:/estrucplan.com.ar/articulos/informetecnico-sobre-aceites-usados-y-sus-usos/

6. Lee SH, Lee S, Kim D, Kim J. Degradation characteristics of waste lubricants under different nutrient conditions. J Hazard Mater. 2007; 143(1-2):65-72.

7. Medina-Moreno SA, Huerta-Ochoa S, Lucho-Constantino CA, Aguilera-Vázquez L, Jiménez-González A, Gutiérrez-Rojas M. Modelado de la biodegradación en biorreactores de lodos de hidrocarburos totales del petróleo intemperizados en suelos y sedimentos. Rev Mex Ing Quím. 2009; 8(3):245-258.

8. Jones JM. Diseño de un Sistema de Reciclaje de Aceite Lubricante Usado. [Tesis]. Valdivia: Universidad Austral de Chile; 2007.

9. Rittman, B. in situ bioremediation. 2 ed. Park Ridge, New Jersey: Noyes Publication; 1994.

10. Rivera L. Microbiología Interiorización del Conocimiento de Forma Significativa y Comprensiva. Machala: Universidad Técnica de Machala; 2015.

11. Souza P. Tecnología de Argilas. São Paulo: Ed. Universidad de São Paulo; 1975.

12. Tuesta E, Vivas M, Sun R, Gutarra A. Modificación Química de Arcillas y su Aplicación en la Retención de Colorantes. Rev Soc Quím Perú. 2005; 71(1):26-36.

13. MacNaughton SJ, Stephen JR, Venosa AD, Davis GA, Chang YJ, White DC. Microbial population changes during bioremediation of an experimental oil spill. Appl Environ Microbiol. 1999; 65(8):3566-74.

14. Xu N, Bao M, Sun P, Li Y. Study on bioadsorption and biodegradation of petroleum hydrocarbons by a microbial consortium. Bioresour Technol. 2013; 149:22-30. 